\title{
Passive microwave measurements of tundra and taiga snow covers in Alaska, U.S.A.
}

\author{
MatThew STURM \\ U.S.A. Cold Regions Research and Engineering Laboratory-Alaska, Building 4070, Fort Wainwright, AK 99703-7860, U.S.A. \\ Thomas C. GRenfell \\ Department of Atmospheric Sciences, AK-40, University of Washington, Seattle, WA 98195, U.S.A. \\ Donald K. PeROVich \\ U.S.A. Cold Regions Research and Engineering Laboratory, 72 Lyme Road, Hanover, NH 03755-1290, U.S.A.
}

\begin{abstract}
The microwave emissivity of two snow covers was measured in Alaska in March, 1990. Observations were made on taiga snow near Fairbanks that was $0.83 \mathrm{~m}$ thick with a $0.55 \mathrm{~m}$ thick basal layer of depth hoar. Other measurements were made on the tundra snow cover at Imnaviat Creek north of the Brooks Range which was 0.27 to $0.64 \mathrm{~m}$ thick and consisted of two or more wind slabs overlying a depth hoar layer 0.14 to $0.26 \mathrm{~m}$ thick. Density, crystal structure, and grain size were similar in tundra and taiga depth hoar layers.

Emissivity was measured at 18.7 and $37 \mathrm{GHz}$ using radiometers mounted on a $1.5 \mathrm{~m}$ tall bipod. Measurements were made on undisturbed snow, and then several snow layers were removed and additional measurements were made. This sequence was repeated until all snow had been removed. Effective emissivity values for the full snow depth ranged from $0.6(37 \mathrm{GHz}, \mathrm{H}-\mathrm{pol})$ to $0.95(18.7 \mathrm{GHz}, \mathrm{V}$-pol) and were similar for both taiga and tundra snow covers. For both snow covers, there was a marked reduction in the effective emissivity $\left(e_{\text {eff }}\right)$ from that of the underlying ground with a maximum reduction of about $30 \%$. All of the reduction was found to occur within the depth hoar layer. Maximum reduction in $e_{\text {eff }}$ could be caused by a depth hoar layer $0.3 \mathrm{~m}$ thick. Overlying wind slab or new snow were nearly "invisible", increasing the effective emissivity only by a small amount due to self-emittance. Thus, it was difficult to distinguish the two different snow covers on the basis of their emissivity, since both contained $0.3 \mathrm{~m}$ of depth hoar or more.
\end{abstract}

\section{INTRODUCTION}

Passive microwave measurements from aircraft and satellites have been used to predict the snow water equivalent in a number of locations (Hall and others, 1982; Burke and others, 1984). The prediction is based on empirically derived inverse relationships between brightness temperature $\left(T_{\mathrm{B}}\right)$ and snow water equivalent (Ulaby and Stiles, 1980; Chang and others, 1982; Bernier, 1987). However, snow stratigraphy, temperature, grain size and shape are also known to affect the microwave emissivity of a snow cover (Mäzler and others, 1980; Hofer and Mäzler, 1980; Kunzi and others, 1982; Burke and others, 1984; Bernier, 1987). In subarctic and arctic snow covers, grain size can vary through two orders of magnitude (from 0.1 to $10 \mathrm{~mm}$ ) due to extreme depth hoar metamorphism. In the high arctic, where wind drifting and the development of wind slab is common, a highly stratified snow cover develops. As a result, the snow cover in the northern regions contains features which limit the usefulness of existing algorithms designed to take advantage of the relationship between microwave emissivity and water equivalent.

Previous work (Hall and others, 1984, 1986; Foster and others, 1991) has documented some of the difficulties in interpreting airborne and satellite-borne radiometer measurements in the north. Results from a transect across central and northern Alaska (Hall and others, 1991) suggest that there is only a poor relationship between snow depth and microwave emissivity in this region.

Because of these difficulties, we decided to investigate the role of grain size and stratigraphy on the passive microwave emissivity. We used near-surface passive microwave radiometers to measure the signature of snow that we could then examine for grain size, stratigraphy, and texture. Our results confirm that grain size and texture can have a dominant effect on the microwave emissivity, and we believe our results explain why some previous efforts to predict snow water equivalent from microwave signals in the arctic and subarctic have encountered difficulties. 


\section{THE EXPERIMENT}

The microwave emissivity of two distinctly different snow covers was measured between 20 and 27 March 1990. The first set of measurements was made on the subarctic taiga snow that develops at Glenn Creek near Fairbanks, Alaska $\left(64^{\circ} 52^{\prime} \mathrm{N}, 147^{\circ} 38^{\prime} \mathrm{W}\right)$. The second was made on the arctic tundra snow that develops at Imnaviat Creek $\left(68^{\circ} 37^{\prime} \mathrm{N}, 149^{\circ} 12^{\prime} \mathrm{W}\right)$, about $190 \mathrm{~km}$ south of Prudhoe Bay, Alaska in the northern foothills of the Brooks Range.

The experiment consisted of measuring the microwave emissivity of the intact snow cover, and then scraping off several layers of snow and repeating the measurements. The process was repeated several times until all the snow had been removed. Final measurements were made on the bare ground. Layers were removed at distinct stratigraphic breaks. In particular, we made sure that at least one measurement was taken at the top of the basal depth hoar layer, after all overlying new and recent snow had been scraped off. With care, we were generally able to produce scraped surface roughnesses that were similar to those of natural snow.

Measurements were made at 18.7 and $37 \mathrm{GHz}$ using radiometers mounted on a $1.5 \mathrm{~m}$-tall bipod that sat on plates resting on the snow surface. The bipod could be rotated through nadir angles of $0^{\circ}$ through $70^{\circ}$; readings were taken every $10^{\circ}$. Two sets of measurements were made at a nadir angle of $50^{\circ}$. At all angles, both horizontal (H) and vertical (V) polarizations were measured. Descriptions of the radiometers and calibration methods can be found in Grenfell and Lohanick (1985). Before and after each set of measurements, the brightness temperature of the sky and of a reference blackbody were measured for calibration purposes. Readings reported here have been reduced to effective emissivity $\left(e_{\text {eff }}\right)$ using the following formula:

$$
e_{\text {eff }}=\left(T_{\mathrm{B}}-T_{\text {sky }}\right) /\left(T_{\text {soil }}-T_{\text {sky }}\right)
$$

where $T_{\mathrm{B}}$ is the brightness temperature of the snow, $T_{\mathrm{sky}}$ is the brightness temperature of the sky, and $T_{\text {soil }}$ is the physical temperature of the soil under the snow. Concurrent with the microwave measurements, snow depth, stratigraphy, density, and texture were measured. Samples of the snow were taken to a cold room and photographed to document the crystal form. Grain size was estimated in the field using a hand lens and grid and measured by sieving. The latter technique is described by Bader and others (1954), Benson (1962) and Sturm (1991).

\section{SNOW COVER TYPES}

The taiga snow cover (defined by Pruitt, 1970; see also Benson, 1982) is found in the boreal forests of Alaska, Canada, Siberia and parts of Scandinavia. It is a lowdensity snow cover composed of a high percentage of depth hoar. The depth hoar forms as a result of several processes. First, due to the continental climate, only a moderate to low amount of winter precipitation falls $(<0.3 \mathrm{~m}$ water equivalent), so the snow cover is thin $(<0.8 \mathrm{~m})$. Second, snow falls are rarely accompanied by wind, hence the density of the deposited snow is low $\left(<250 \mathrm{~kg} \mathrm{~m}^{3}\right)$ and it is highly permeable. Third, consistently low air temperatures $\left(<-20^{\circ} \mathrm{C}\right)$ and warm snow/ ground interface temperatures $\left(>-5^{\circ} \mathrm{C}\right)$ create strong vertical temperature gradients across the snow. By March, after the snow has been subjected to these strong temperature gradients for more than 150 days, the basal $75 \%$ or more of the snow cover can be depth hoar.

The tundra snow cover, found in the treeless areas of the arctic and subarctic, forms a thin $(<0.5 \mathrm{~m})$ veneer over the tundra. Due to strong and persistent winds, this veneer is composed chiefly of one or more wind slabs overlying a basal depth hoar layer. The first snowfall of the year fills in the spaces between tundra tussocks. Under the influence of strong temperature gradients, this basal layer rapidly metamorphoses into depth hoar. Wind storms cap the basal layer with dense $\left(>350 \mathrm{~kg} \mathrm{~m}^{-3}\right)$ slabs of snow. Subsequent snowfalls produce depth hoar layers or wind slabs depending upon whether they fall during calm or windy periods.

Both tundra and taiga snow covers contain coarsegrained depth hoar crystals of unusually large size. In both types of snow covers, a five-fold metamorphic sequence develops. This sequence has been described for the taiga snow by Sturm (1991) and Sturm and Johnson (1991). In the sequence (1) new snow metamorphoses into (2) solid-type depth hoar (described by Akitaya, 1974), then into (3) striated cups and chains of cups (described by Sommerfeld and LaChapelle, 1970; Trabant and Benson, 1972; and Colbeck, 1986), into (4) squat prisms, and finally into (5) elongated prisms (International Classification for Seasonal Snow on the Ground, Type 5c). Exotic forms, such as scrolled crystals, also occur in the latter phases of the sequence. Grain size increases from sub-millimeter grains (solid-type depth hoar) to grains that can exceed $30 \mathrm{~mm}$ in length (elongated prisms).

\section{RESULTS}

Seven sets of microwave measurements were made during the study. Four sets were made on taiga snow at Glenn Creek between 20 and 23 March 1990; three sets were made on tundra snow at Imnaviat Creek between 26 and 27 March. At Glenn Creek, measurements were made in a forest clearing where snow depth ranged between 0.73 and $0.83 \mathrm{~m}$. At Imnaviat Creek measurements were made in three different locations: on a ridge crest (depth $=0.27$ $\mathrm{m}$ ), in the valley bottom (depth $=0.56 \mathrm{~m}$ ), and in a deep snow drift in the lee of a building (depth $=0.64 \mathrm{~m}$ ). During the experiment snow temperatures were well below freezing and the snow was dry.

The effective emissivity $\left(e_{\text {eff }}\right)$ as a function of snow depth is shown in Figure 1 (tundra snow) and Figure 2 (taiga snow) for a nadir angle of $50^{\circ}$. Results for other nadir angles were similar, but at $50^{\circ}$ we observed nearmaximum changes in $e_{\text {eff }}$ as a function of snow depth. $50^{\circ}$ is also the view angle of the DMSP Special Sensor Microwave Imager (SSMI) and the Nimbus-7 Scanning Mulitchannel Microwave Radiometer (SMMR) satellite sensors; thus we concentrate on that angle here. For all measurement sets, the pattern is similar: there is a marked reduction in $e_{\text {eff }}$ between the base of the snow and a 

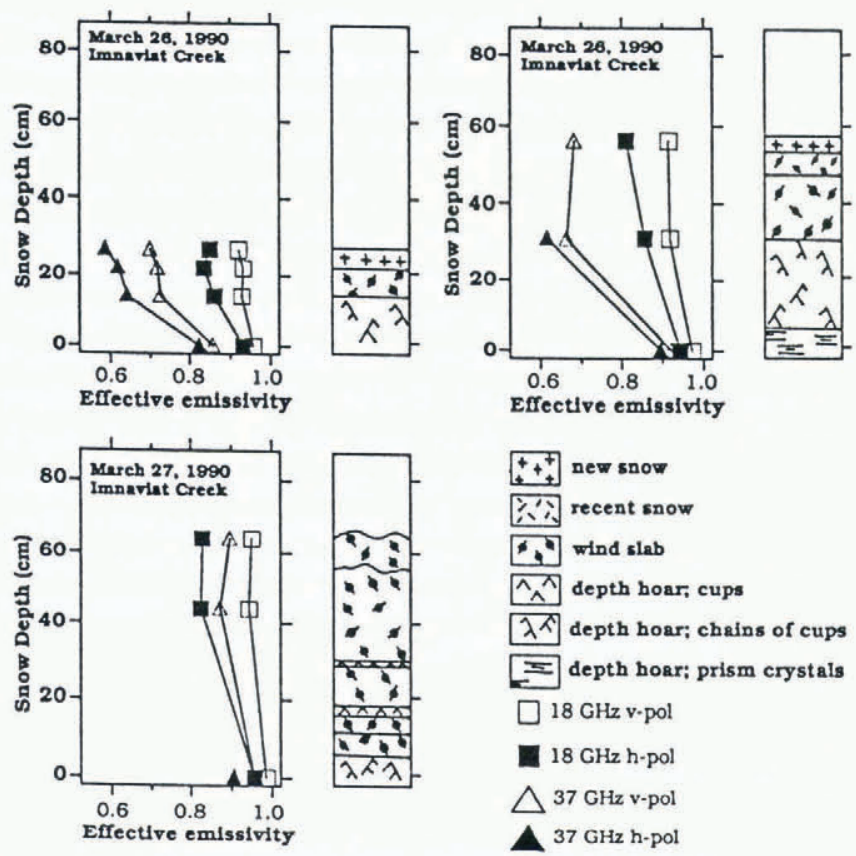

Fig. 1. Effective emissivity ( $\left.e_{\text {eff }}\right)$ as a function of snow depth for tundra snow (nadir angle $=50^{\circ}$ ). The stratigraphy is shown adjacent to the main figure.
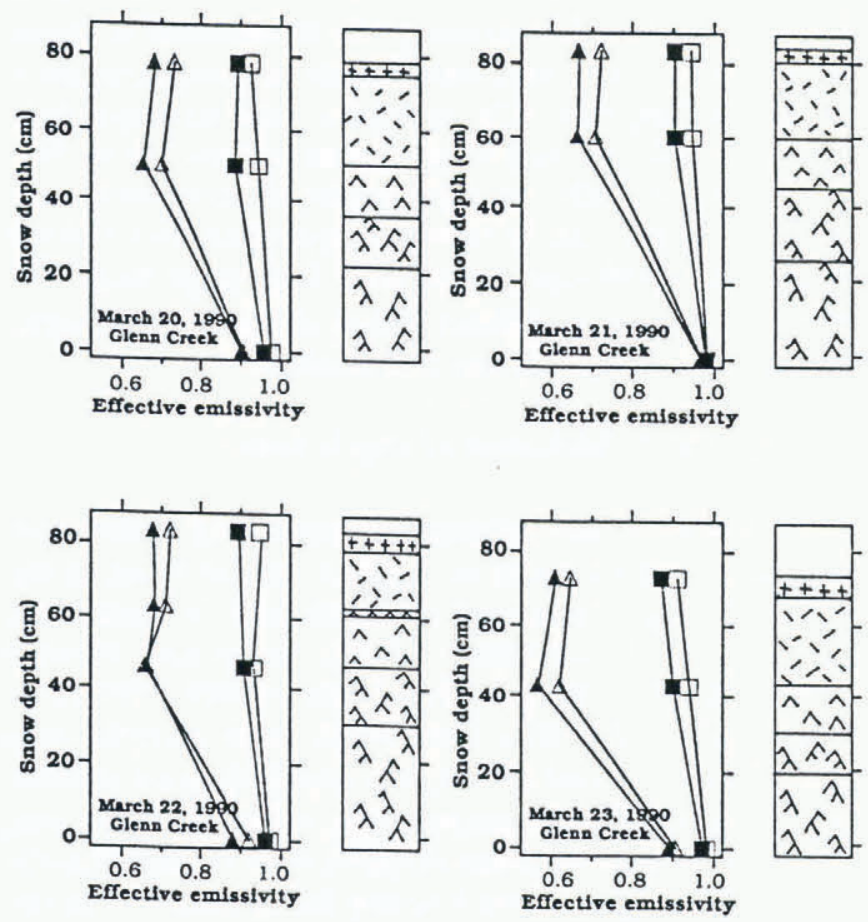

Fig. 2. Effective emissivity ( $\left.e_{\mathrm{eff}}\right)$ as a function of snow depth for taiga snow (nadir angle $=50^{\circ}$ ). The stratigraphy is shown adjacent to the main figure. Symbols are the same as in Figure 1.

height of 0.3 to $0.5 \mathrm{~m}$. Above that, $e_{\text {eff }}$ increases slightly (37 and some $18.7 \mathrm{GHz}$ ) or is constant $(18.7 \mathrm{GHz})$. The reduction in $e_{\text {eff }}$ averages about $30 \%$ for $37 \mathrm{GHz}$, and $10 \%$ to $15 \%$ for $18.7 \mathrm{GHz}$. Minimum values of $e_{\text {eff }}$ occur for approximately the same thickness of both taiga and tundra snow. This height roughly corresponds with the transition between depth hoar and recent snow (see stratigraphic sections in Figs 1 and 2). Where the total snow depth is less than $0.40 \mathrm{~m}$, minimum values of $e_{\text {eff }}$ occur for the full snow thickness.

Despite major differences in the character of the snow covers, the value of $e_{\text {eff }}$ at the snow surface, prior to removing any snow layers, was not significantly different at Glenn Creek (taiga snow) from that at Imnaviat Creek (tundra snow). For example, at $37 \mathrm{GHz}, \mathrm{H}$-polarization, the reading at the top of the snow at Glenn Creek was $0.71 \pm 0.03$, compared to $0.69 \pm 0.01$ at Imnaviat Creek. The wind drift measured on $27 \mathrm{March}$ at Imnaviat Creek (Fig. 1) is an exception to this pattern. At the surface of the drift, we recorded much higher values of $e_{\text {eff }}$ at both 18.7 and $37 \mathrm{GHz}$ than elsewhere. As discussed later, this may be because there was considerably less depth hoar present in the stratigraphic column of the drift than in the other tests.

We have tried to isolate the effect of depth hoar on the effective emissivity. In Figure 3, only values of $e_{\text {eff }}$ measured from depth hoar are plotted. We have combined the measurements from both locations because the depth hoar crystals at Imnaviat Creek and Glenn Creek were virtually indistinguishable. To combine all

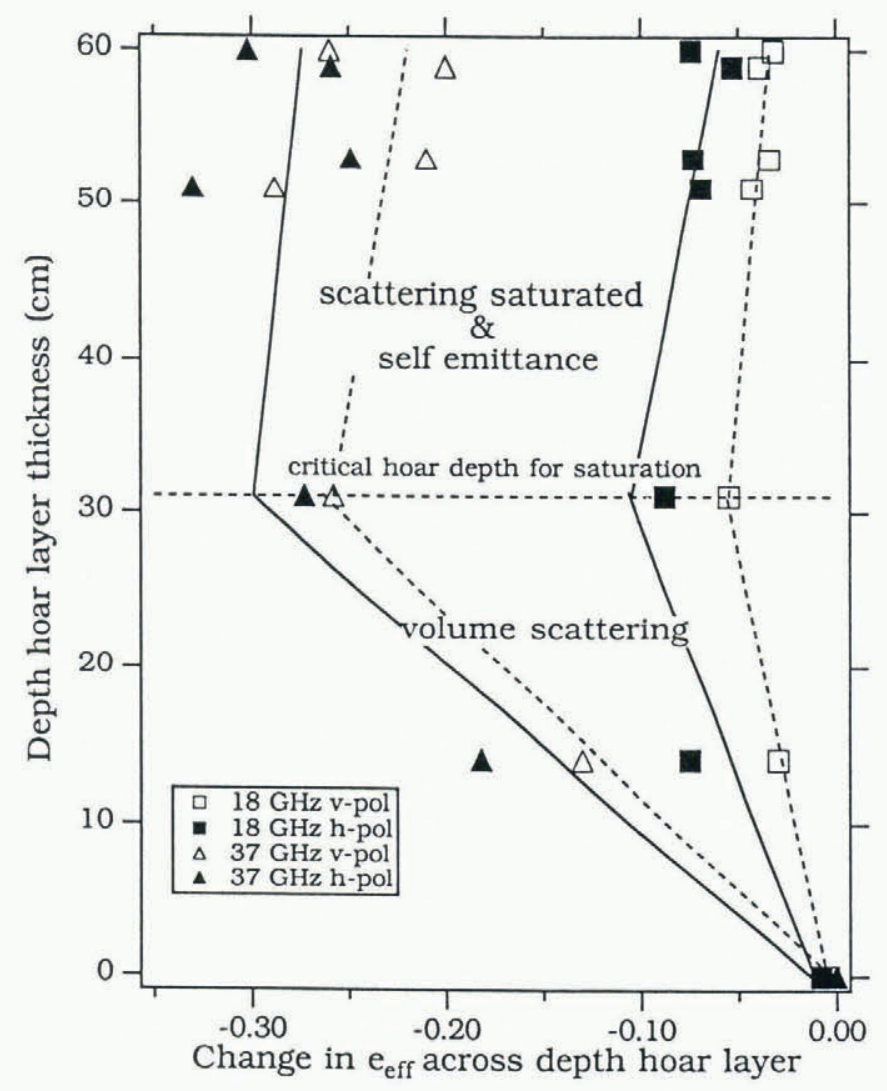

Fig. 3. The change in effective emissivity $\left(e_{\mathrm{eff}}\right)$ as a function of depth hoar thickness. Results from Imnaviat Creek (tundra) and Glenn Creek (taiga) are combined here. Because of the limited number of data points, the critical depth appears to be the same for both 18.7 and $37 \mathrm{GHz}$. However, it is more likely that the critical depth is greater than $0.3 \mathrm{~m}$ for $18.7 \mathrm{GHz}$, and is less than $0.3 \mathrm{~m}$ for $37 \mathrm{GHz}$. 


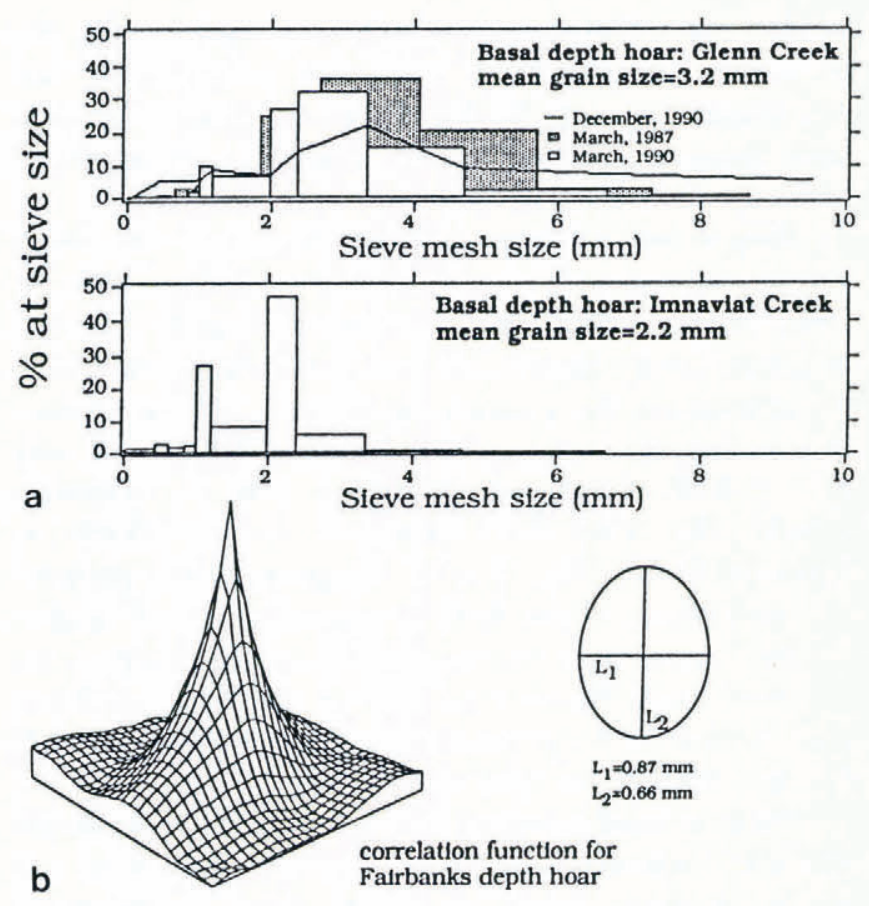

Fig. 4. a: Grain size distribution for samples from Glenn Creek and Imnaviat Creek. For comparison, distribution curves for depth hoar samples taken in March, 1987 and December, 1990 in Fairbanks are shown. The December, 1990 sample was also used in the calculations of correlation lengths. $b$ : Correlation function for depth hoar sample of December, 1990. The function is slightly asymmetrical. Correlation lengths calculated from the axes of the function are marked as $L_{1}$ and $L_{2}$.

the sets, readings from each set have been offset by subtracting the value of $e_{\text {eff }}$ measured over bare ground. The results indicate that there is a marked reduction in $e_{\text {eff }}$ up to a depth hoar thickness of approximately $0.3 \mathrm{~m}$, but that for a greater thickness of depth hoar there is no further reduction in the emissivity. Instead, for depth hoar thicknesses greater than approximately $0.3 \mathrm{~m}$, there is a small but definite increase in $e_{\text {eff }}$ (Fig. 3). Because of the limited number of data points, the critical depth appears to be the same for both 18.7 and $37 \mathrm{GHz}$. However, it is more likely (while still being consistent with the data) that the critical depth is greater than $0.3 \mathrm{~m}$ for $18.7 \mathrm{GHz}$, and is less than $0.3 \mathrm{~m}$ for $37 \mathrm{GHz}$. More data are needed to delineate this trend.

The grain size distribution of depth hoar was examined by sieving and stereology. Samples from Glenn Creek and Imnaviat Creek were sieved using standard practices for sedimentary geology (Friedman and Sanders, 1983); results are shown in Figure 4. The applicability of sieving technique for depth hoar has been discussed by Sturm (1991); results from this study are consistent with results determined for taiga snow during a previous study (Fig. 4a). Mean depth hoar grain size was between 3 and $4 \mathrm{~mm}$, with a skewed distribution that included some grains as large as $10 \mathrm{~mm}$.

Unfortunately, due to the melting of our samples, we were unable to make stereological measurements on the snow from which the microwave measurements were made. However, in December 1990, we obtained new samples of depth hoar near Fairbanks that had a similar texture to the snow samples collected during the microwave experiment. Sieve results from the new samples were also similar to the microwave samples (Fig. 4a). This gave us some confidence that stereological measurements made on the new samples would be generally applicable to the microwave measurements. Stereological measurements were made using techniques described by Davis and Dozier (1989). From plane polished sections cut from cast blocks of basal depth hoar, we have calculated the correlation length $(\approx 0.8 \mathrm{~mm})$ and plotted the correlation function (Fig. 4b) (Vallese and Kong, 1981; Perovich and Gow, 1991). The correlation length is about $25 \%$ of the mean grain size as measured by sieving.

\section{DISCUSSION}

\section{Differentiation of tundra and taiga snow}

Our results suggest that it is difficult to differentiate tundra snow from taiga snow solely on the basis of passive microwave signals at 18.7 and $37 \mathrm{GHz}$. The emissivity at the top of the snow cover was approximately the same for all the measurements at Glenn Creek, and did not differ from the values obtained at Imnaviat Creek by a significant amount (excluding the measurements made on drift snow). Yet our measurements were made on snow depths ranging from 0.27 to $0.83 \mathrm{~m}$, with corresponding water equivalent values ranging from 0.09 to $0.25 \mathrm{~m}$. Not only were we unable to differentiate the snow covers on the basis of snow depth or water equivalent, but also we could not differentiate tundra snow from taiga snow. Yet these are distinctly different snow covers with different stratigraphy and grain size distributions.

\section{"Saturation" thickness of depth hoar}

The reason for the difficulty in separating these snow covers using their microwave signals can be found in the unusually high percentage of depth hoar in both snow covers. Mäzler and others (1980), Hofer and Mätzler (1980), Bernier (1987), Hall and others (1986, 1991), and others have noted that large depth hoar crystals, with their hollow striated shapes, are unusually good volume scatterers. Our results confirm this, but also suggest that there is a critical thickness of depth hoar (approximately $0.3 \pm 0.1 \mathrm{~m}$ ) within which nearly full attenuation of the microwaves emitted from the underlying ground occurs. It is likely that this critical thickness is less than $0.3 \mathrm{~m}$ for $37 \mathrm{GHz}$, and is greater than $0.3 \mathrm{~m}$ for $18.7 \mathrm{GHz}$, though the resolution of our data is insufficient to show this trend. In general, however, for depth hoar thickness ranging up to $0.3 \mathrm{~m}$, the microwaves emitted by the ground are progressively attenuated with increasing depth due to volume scattering by the snow grains. For thicknesses greater than $0.3 \mathrm{~m}$, no further attenuation occurs. Instead, self-emittance by the overlying fine-grained snow increases the emissivity recorded from the snow surface. Thus, in Figure 3 we have labeled the curve of $e_{\text {eff }}$ vs snow depth in two distinct sections. Between 0 and 
$0.3 \mathrm{~m}$, volume scattering due to the large depth hoar crystals dominates. At approximately $0.3 \mathrm{~m}$, saturation has been achieved, and self-emittance begins to increase the effective emissivity.

The rate of increase due to self-emittance at $37 \mathrm{GHz}$ is about $1.1 \mathrm{~dB} \mathrm{~m}^{-1}$ for the wind slab overlying the depth hoar at Imnaviat Creek. It ranges from 0.8 to $1.4 \mathrm{~dB} \mathrm{~m}^{-1}$ for the new and recent snow at Glenn Creek. In contrast, attenuation rates due to volume scattering by depth hoar range from -0.6 to $-2.7 \mathrm{~dB} \mathrm{~m}^{-1}$ for $18.7 \mathrm{GHz}$, and from -4.5 to $-10.3 \mathrm{~dB} \mathrm{~m}^{-1}$ for $37 \mathrm{GHz}$. These attenuation rates are approximately an order of magnitude greater than the rate of increase of the microwave signal due to self emittance. Thus, if enough depth hoar is present and a saturation level achieved, the addition of overlying snow, whether new snow or wind slab, only results in a small (and difficult to detect) change in the microwave signal.

The existence of a "saturation level" due to volume scattering of snow has been observed before. Kunzi and others (1982) noted that there was a linear relationship between snow depth and gradient temperature (GT) (a ratio of brightness temperatures) up to a critical snow depth of about $0.5 \mathrm{~m}$; for greater depths they found no further change in GT. Our findings are consistent with theirs, though we would attribute the differences in critical snow depth at saturation $(0.3 \mathrm{~m}$ vs $0.5 \mathrm{~m})$ to the greater volume scattering associated with depth hoar than with other types of snow.

\section{Depth hoar grain size and correlation length}

The enhanced volume scattering of microwave emission by depth hoar must be due to (1) the ornate grain shapes, and/or (2) the fact that the grain size distribution contains a considerable number of large outlyers. Vallese and Kong (1981) found that correlation lengths corresponded to actual sizes of ice particles in coarse and finegrained snow samples. Our results, however, indicate that correlation lengths are about $25 \%$ of the actual (or sieve) grain size for depth hoar crystals. Hall and others (1986) needed to make a comparable reduction in effective grain size in order to force the results of their depth hoar model to be consistent with the observed microwave emissivity.

\section{CONCLUSIONS}

Tundra and taiga snow differ greatly in depth, density and stratigraphic character, yet they have one common textural attribute: both types of snow contain a basal layer of depth hoar that often exceeds $0.3 \mathrm{~m}$ thickness. As a result, differentiation of the two types of snow covers, or even determination of their water equivalent from millimeter wavelength passive microwave emissivity, is difficult. For $37 \mathrm{GHz}$, approximately $0.3 \mathrm{~m}$ of depth hoar is sufficient to greatly attenuate the microwave emissivity of the underlying ground. Additional snow above the depth hoar layer increases the microwave signal due to self-emittance, but this increase occurs at about one tenth the rate that volume scattering decreases the signal. The net result is that two highly dissimilar snow covers can look identical based on their microwave emissivity.

Other researchers (Kunzi and others, 1982) have recognized that at $37 \mathrm{GHz}$ there is a "saturation" thickness of snow at which the signal from the underlying ground has been greatly attenuated. However, the saturation thickness they found $(0.5 \mathrm{~m})$ was considerably greater than we have found for depth hoar $(0.3 \mathrm{~m})$. This difference is probably attributable to the large ornate grains in depth hoar.

\section{ACKNOWLEDGEMENTS}

This work was supported by DA Project 4A762784AT42 Cold Regions Engineering and Technology: Work Unit 73S26-Areal Distribution of Snow Properties. J.B. Johnson, D. Solie, and C.S. Benson were of great help during the field work.

\section{REFERENCES}

Akitaya, E. 1974. Studies on depth hoar. Contrib. Inst. Low Temp. Sci., Ser. A, 26.

Bader, H., R. Haefeli, E. Bucher, J. Neher, O. Eckel and C. Thams. 1954. Snow and its metamorphism. SIPRE Translation 14.

Benson, C. S. 1962. Stratigraphic studies in the snow and firn of the Greenland ice sheet. SIPRE Res. Rep. 70.

Benson, C. S. 1982. Reassessment of winter precipitation on Alaska's Arctic slope and measurements of the flux of wind blown snow. University of Alaska. Geophysical Institute. Report UAG R-288.

Bernier, P.Y. 1987. Microwave remote sensing of snowpack properties: potential and limitations. Nord. Hydrol., 18(1), 1-20.

Burke, H.H.K., C.J. Bowley and J. C. Barnes. 1984. Determination of snowpack properties from satellite passive microwave measurements. Remote Sensing Environ., 15, 1-20.

Chang, A. T. C., J. L. Foster, D. K. Hall, A. Rango and B. K. Hartline. 1982. Snow water equivalent estimation by microwave radiometry. Cold Reg. Sci. Technol., 5(3), 259-267.

Colbeck, S. C. 1986. Classification of seasonal snow cover crystals. Water Resour. Res., 22(9), 59s-79s.

Colbeck, S. and 7 others. The international classification for seasonal snow on the ground. Wallingford, Oxfordshire, International Association for Scientific Hydrology.

Davis, R. E. and J. Dozier. 1989. Stereological characterization of dry alpine snow for microwave remote sensing. Adv. Space Res., 9(1), 245-251.

Foster, J. L., A. T. C. Chang, D. K. Hall and A. Rango. 1991. Derivation of snow water equivalent in boreal forests using microwave radiometry. Arctic, 44, Supple-

Friedman, G. M. and J.E. Sanders. 1983. Principles of sedimentology. New York, John Wiley and Sons.

Grenfell, T.C. and A.W. Lohanick. 1985. Temporal variations of the microwave signatures of sea ice during the late spring and early summer near Mould Bay, NWT. 7. Geophys. Res., 90(C3), 5063-5074.

Hall, D. K., J. L. Foster and A. T.C. Chang. 1982. Measurement and modeling of microwave emission from forested snowfields in Michigan. Nord. Hydrol., 13(3), 129-138. 
Hall, D. K., J. L. Foster and A.T.C. Chang. 1984. Regional differences in snowpacks in the northern U.S. as seen by the Nimbus-7 SMMR. Proc. East. Snow Conf. Forty-first annual meeting, 67-74.

Hall, D. K., A.T.C. Chang and J. L. Foster. 1986. Detection of the depth-hoar layer in the snow-pack of the Arctic coastal plain of Alaska, U.S.A. using satellite data. F. Glaciol., 32(110), 87-94.

Hall, D. K. and 6 others. 1991. Passive microwave remote and in situ measurements of Arctic and subarctic snow covers in Alaska. Remote Sensing Environ., 38(3), 161172.

Hofer, R. and C. Mätzler. 1980. Investigations on snow parameters by radiometry in the 3- to $60-\mathrm{mm}$ wavelength region. 7. Geophys. Res., 85(C1), 453-460.

Kunzi, K.F., S. Patil and H. Rott. 1982. Snow-cover parameters retrieved from Nimbus-7 scanning multichannel microwave radiometer (SMMR) data. IEEE Trans. Geosci. Remote Sensing, GE-20(4), 452-467.

Mätzler, C., E. Schanda, R. Hofer and W. Good. 1980. Microwave signatures of the natural snow cover at Weissfluhjoch. In Rango, A., ed. Microwave remote sensing of snowpack properties. Washington, DC, National Aeronautics and Space Administration, 203-223. (Conference Publication 2153.)

Perovich, D. K. and A.J. Gow. 1991. A statistical description of the microstructure of young sea ice. 7 . Geophys. Res., 96(C9), 16,943-16,953.

Pruitt., W. O., Jr. 1970. Some ecological aspects of snow. In Ecology of the Subarctic Regions. Proceedings of the Helsinki Symposium. Paris, UNESCO, 83-99.

Sommerfeld, R.A. and E. LaChapelle. 1970. The classification of snow metamorphism. J. Glaciol., 9(55), 3-17.

Sturm, M. 1991. The role of thermal convection in heat and mass transport in the subarctic snow cover. CRREL Rep. 91-19.

Sturm, M. and J. B. Johnson. 1991. Natural convection in the subarctic snow cover. 7. Geophys. Res., 96(B7), 11,657-11,671.

Trabant, D. and C. S. Benson. 1972. Field experiments on the development of depth hoar. Geol. Soc. Am. Mem. 135, 309-322.

Ulaby, F. T. and W.H. Stiles. 1980. The active and passive microwave response to snow parameters. 2 . Water equivalent of dry snow. 7. Geophys. Res., 85(C2), 1045-1049.

Vallese, F. and J.A. Kong. 1981. Correlation function studies for snow and ice. J. Appl. Phys., 52(8), 49214925.

The accuracy of references in the text and in this list is the responsibility of the authors, to whom queries should be addressed. 